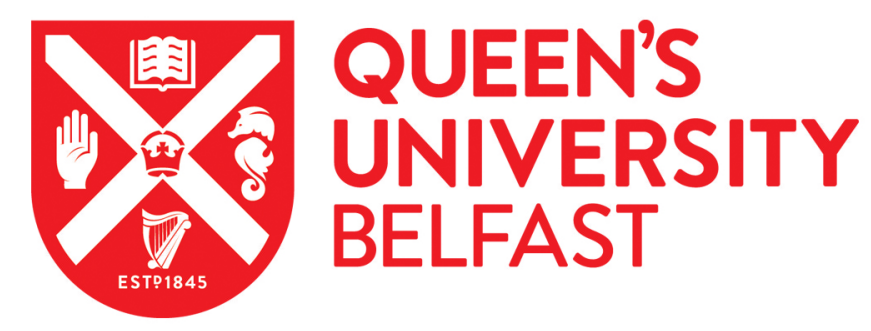

\title{
Smart inks as photocatalytic activity indicators of self-cleaning paints
}

Baudys, M., Krysa, J., \& Mills, A. (2017). Smart inks as photocatalytic activity indicators of self-cleaning paints. Catalysis Today, 280(1), 8-13. https://doi.org/10.1016/j.cattod.2016.04.041

\author{
Published in: \\ Catalysis Today
}

Document Version:

Peer reviewed version

Queen's University Belfast - Research Portal:

Link to publication record in Queen's University Belfast Research Portal

\section{Publisher rights}

(c) 2016 Elsevier B. V.

This is an open access article published under a Creative Commons Attribution-NonCommercial-NoDerivs License

(https://creativecommons.org/licenses/by-nc-nd/4.0/), which permits distribution and reproduction for non-cjavascript:void(0);ommercial purposes, provided the author and source are cited.

\section{General rights}

Copyright for the publications made accessible via the Queen's University Belfast Research Portal is retained by the author(s) and / or other copyright owners and it is a condition of accessing these publications that users recognise and abide by the legal requirements associated with these rights.

Take down policy

The Research Portal is Queen's institutional repository that provides access to Queen's research output. Every effort has been made to ensure that content in the Research Portal does not infringe any person's rights, or applicable UK laws. If you discover content in the Research Portal that you believe breaches copyright or violates any law, please contact openaccess@qub.ac.uk. 


\section{Smart Inks as Photocatalytic Activity Indicators of Self-cleaning Paints}

\section{Baudys ${ }^{1}$, J. Krýsa ${ }^{* 1}$ and A. Mills ${ }^{2}$}

${ }^{1}$ University of Chemistry and Technology Prague, Department of Inorganic Technology, Technická 5, CZ 16628 Prague 6, Czech Republic, e-mail: krysaj@vscht.cz

${ }^{2}$ Queens University Belfast, School of Chemistry and Chemical Engineering, David Keir Building, Stranmillis Road, Belfast, BT5 9AG, UK

Key words: self-cleaning paints, Resazurin ink, Acid Violet 7 ink, weathering, QUV

Abstract

Smart inks as a redox indicators of photocatalytic activity were applied on several paints with acrylic and silicate binder exposed to accelerated weathering test. The results show, that selfcleaning paints need some weathering to develop full photocatalytic activity. On the other side weathering may negatively influence the durability of the paint as shown for a silicate based exterior paint, which was significantly degraded after 350 hours of weathering test. Smart inks proved to be suitable and rapid indicators of paint photoactivity. Resazurin ink is convenient only for unexposed paint with low photocatalytic activity while an Acid Violet 7 ink was appropriate for most of the paints, especially those that were weathered.

\section{Introduction}

Commercial self-cleaning paints contain, besides the usual pigments and fillers, particles of a photocatalyst such as $\mathrm{TiO}_{2}$ or $\mathrm{ZnO}$ which act as a sensitizer for the photocatalytic process, i.e. the mineralisation of organic and inorganic pollutants via their photo-sensitised oxidation by oxygen. Current commercial paint applications are mainly focused on exterior facade paints which, via the photocatalytic processes, are not susceptible to soiling by organic pollutants or the growth of microorganisms, fungi and algae [1-3].

Photocatalytic paints are also widely used to improve the air quality in the environment, via the removal of $\mathrm{NO}_{\mathrm{x}}$ [4] and/or ammonia [5] , the former originating mainly from car exhausts and the latter from car exhausts and farm manure. The development of photoactive paints may seem paradoxical, because paint manufactures use pigments, e.g. $\mathrm{TiO}_{2}$ that are specifically designed to be photocatalytically inactive, as they would otherwise photo- 
oxidise the polymer binder and cause photochalking. Therefore, paint pigments are often based on low active or non-active rutile titania particles, surface treated with alumina or silica in order to ensure photocatalytic passivity. Such pigments also stabilise paints for the exterior use as they act as a highly effective solar UV block [6]. In the formulation of any selfcleaning paint it is important to find a compromise between photocatalytic activity and paint lifetime [7].

This work is a continuation of a previous report [8] from this group which focused on the effect of weathering of acrylic photocatalytic paints, containing $\mathrm{TiO}_{2}$ and $\mathrm{ZnO}$, on their photocatalytic activities, as assessed using a test based on the photocatalysed oxidative bleaching of Acid Orange 7 (AO7) in solution. The latter test is rather cumbersome and timeconsuming to use. As an alternative there is an increasing interest in photocatalytic activity indicator inks, which work via the reduction of dye, as they are fast, simple and easy to use. Encouragingly, they appear to generate results that correlate directly with those obtained using the more conventional, but much more time-consuming oxidative tests, such as those based on AO7 bleaching [9] or stearic acid removal [10-12].

Photocatalytic activity indicator inks work on the basis that: (i) the ink film is deposited onto the surface of the photocatalytic film under test, such as a photocatalytic paint; (ii) upon ultra-band gap illumination of the underlying photocatalyst, the photogenerated holes oxidise a sacrificial electron donor, present in the ink, such as glycerol. The photogenerated electrons are then free to reduce the redox dye also present in the ink and in doing so change the colour of the ink. As a consequence the rate of change of the ink, as measured by UV/Visible spectroscopy or using digital photography, vide infra, provides a direct measure of the photocatalytic activity of the ink. The redox dye is chosen so that it is readily and irreversibly reduced by the photogenerated electrons and that the associated colour changes striking [13]. Dyes used previously include: resazurin (Rz; blue to pink) and dichloroindophenol (DCIP; blue to colourless) [14-19]. The objective of the current work is to use photocatalytic activity indicator inks to assess the activities of several self-cleaning paints exposed to simulated weathering. For this purpose a recently introduced redox dye, acid violet 7, (AV7; pink to colourless) [20] is conveniently used.

\section{Experimental}

\subsection{Paints preparation}

A series of paints were prepared by mixing the pigments, fillers, photocatalyst and special agents in acrylic water based dispersion. The amount of photocatalyst in paint was set to 8 
wt.\%. The typical "photocatalytic" paint used here comprised of: $243 \mathrm{~g}$ of acrylic dispersion, $40 \mathrm{~g}$ of the $\mathrm{TiO}_{2}$ photocatalyst, $55 \mathrm{~g}$ of rutile non photocatalytic $\mathrm{TiO}_{2}$ pigment (Kronos 2190), $46 \mathrm{~g}$ of $\mathrm{BaSO}_{4}$ (Sachtleben) and additives such as rheological, antifoaming and wetting agent. The $\mathrm{TiO}_{2}$ photocatalyst used was Evonik $\mathrm{TiO}_{2} \mathrm{P} 25$, consisting of $71 \%$ of anatase and $29 \%$ of rutile (XRD) with BET surface area about $56 \mathrm{~m}^{2} / \mathrm{g}$. For comparison, the photocatalytic activities were also determined for two different commercial self-cleaning, photocatalytic façade paints, namely: an interior paint (IP) and a silicate based exterior paint (EP)

In all cases, the paint sample under test was applied to a soda lime glass slide support using a universal applicator ZUVA 2000 (Zehnter, Germany), set to generate a wet film thickness of $150 \mu \mathrm{m}$, which typically dried (24 hours) to a thickness of 80-100 $\mu \mathrm{m}$. Weathered samples were produced by exposing them in a weathering unit (QUV, Q-Lab, USA) up to 600 hours using the following cycle: i) UV irradiation (maximum $340 \mathrm{~nm}$ ), intensity $1 \mathrm{~W} / \mathrm{m}^{2}, 8 \mathrm{~h}$, (ii) spraying with water, $7 \mathrm{dm}^{3} / \mathrm{min}, 4 \mathrm{~min}$, (iii) condensation of steam, temperature $70{ }^{\circ} \mathrm{C}$, $4 \mathrm{~h}$ and (iv) spraying with water, $7 \mathrm{dm}^{3} / \mathrm{min}, 4 \mathrm{~min}$.

\subsection{Photocatalyst activity indicator inks}

A typical ink consisted of: $10 \mathrm{~g}$ of $1.5 \mathrm{wt}$ \% of hydroxyethyl cellulose, $1 \mathrm{~g}$ of glycerol, $20 \mathrm{mg}$ of polysorbate 20 surfactant. In the case of the Resazurin ink the amount of dye added was $10 \mathrm{mg}$, in the case of the Acid Violet $7 \mathrm{ink}, 25 \mathrm{mg}$ of dye were added. The amount of dye in the ink has been chosen based on the previous experience with aim to achieve decolourization times in the range from 1-90 min. Both dyes were supplied by Aldrich Chemicals and used as received. In all cases the indicator ink was applied to the paint samples

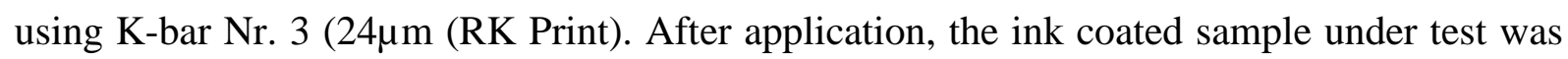
dried for 1 hour in the dark and then exposed to UVA light from black light (BL) lamp $\left(\lambda_{\max }(\right.$ emission $)=352 \mathrm{~nm}$; irradiance: $\left.2 \mathrm{~mW} / \mathrm{cm}^{2}\right)$ [21]. Throughout the irradiation, digital images of the ink-coated samples under test were periodically recorded using a handheld document scanner (CopyCat). The central part of the ink-coated digital image of each sample was then analysed in terms of its red (R), green (G) and blue (B) components using a free graphical software package, Image [13]. The plot of the colour component that changed most significantly ( $R$ for the Rz ink and G from the AV7 ink) vs. time of UV exposure allowed the time to bleach $90 \%$ of the colour, $\operatorname{tb}(90)$, to be calculated for the material under test. In all this work, at least six identical samples were tested for each material under investigation.

\section{Results and discussion:}


At first the photocatalytic activities of the unweathered $\mathrm{TiO}_{2}$ in-house paint and commercial silicate based exterior paint were assessed using $\mathrm{Rz}$ as the photocatalyst activity indicator ink. The results of this work, in the form of plots of $\mathrm{R}(\mathrm{t})$ versus irradiation time $\mathrm{t}$, are, for the six samples of each paint, illustrated in figures 1 and 2 respectively. In both cases, plots of $\mathrm{R}(\mathrm{t})$ versus irradiation time $\mathrm{t}$ exhibit a clear peak at the point where the colour of the film disappeared or stopped changing. The identification of the exact time when all photobleaching (of the colour component under investigation) of the activity indicator ink has ceased is difficult and so the time taken for $90 \%$ of the overall bleaching process is determined instead (Ttb 90) [20]. For each trace in Figs 1 and 2, this point is identified by a solid red square. Comparing Figs 1 and 2 we can see dramatic differences in the Ttb (90) values for the two different paint samples. Thus, the $\mathrm{TiO}_{2}$ in-house paint exhibits a reasonable photocatalytic activity, whereas in the case of the commercial exterior paint, its photocatalytic activity is much lower and so its average Ttb value is about 40 times higher. In the case of a commercial interior paint (bleaching curve not shown here), its photocatalytic activity was so high (colour change take place in few seconds that the Rz ink test was adjudged as not suitable for assessing the activity of this paint. As a consequence, for this purpose, another, less sensitive ink based on the dye AV7 was used following its recent development [20].

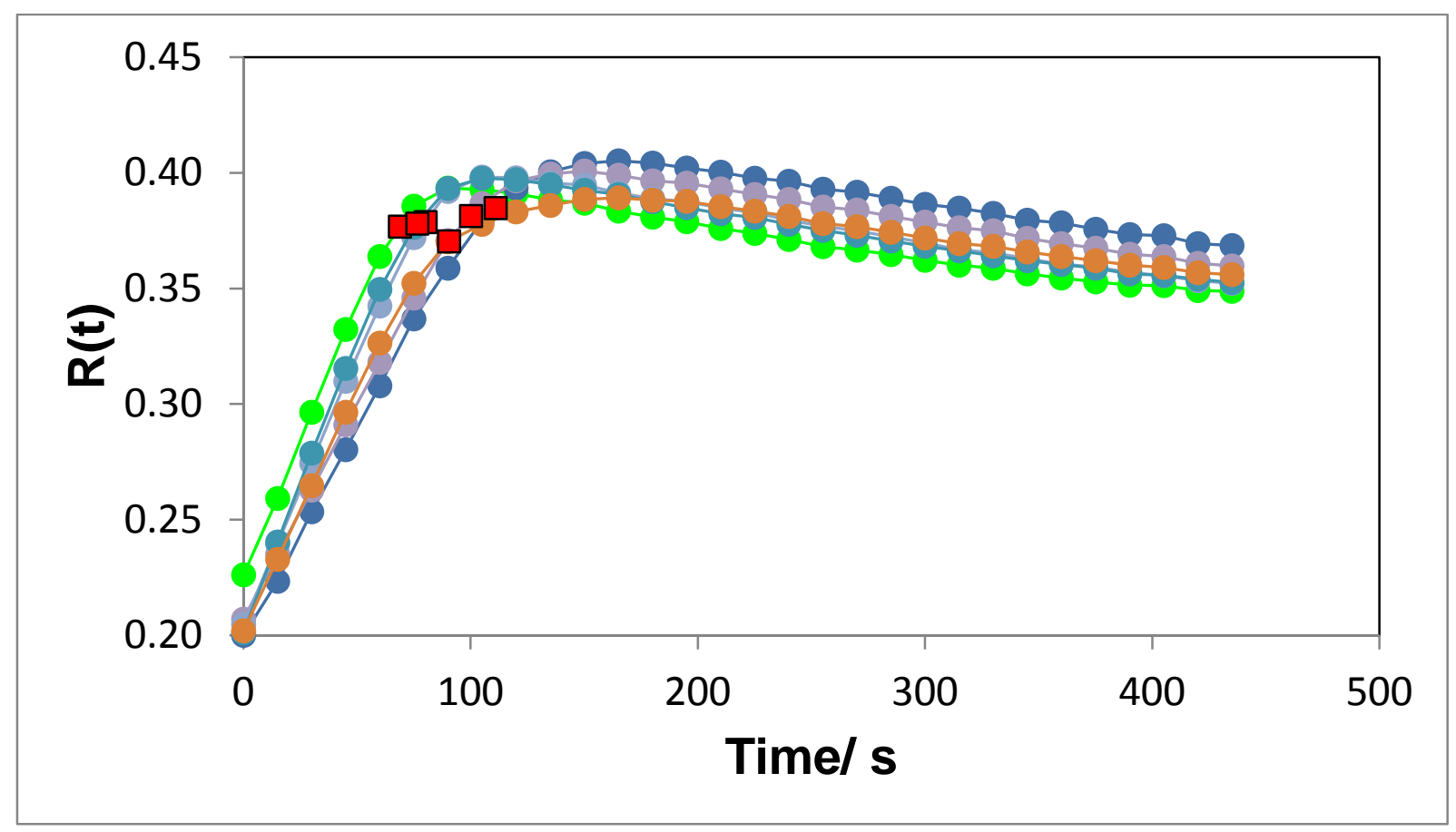

Fig. 1 Plot of $\mathrm{R}(\mathrm{t})$ depending on exposition time for $\mathrm{Rz}$ ink on $\mathrm{TiO}_{2}$ in-house paint 


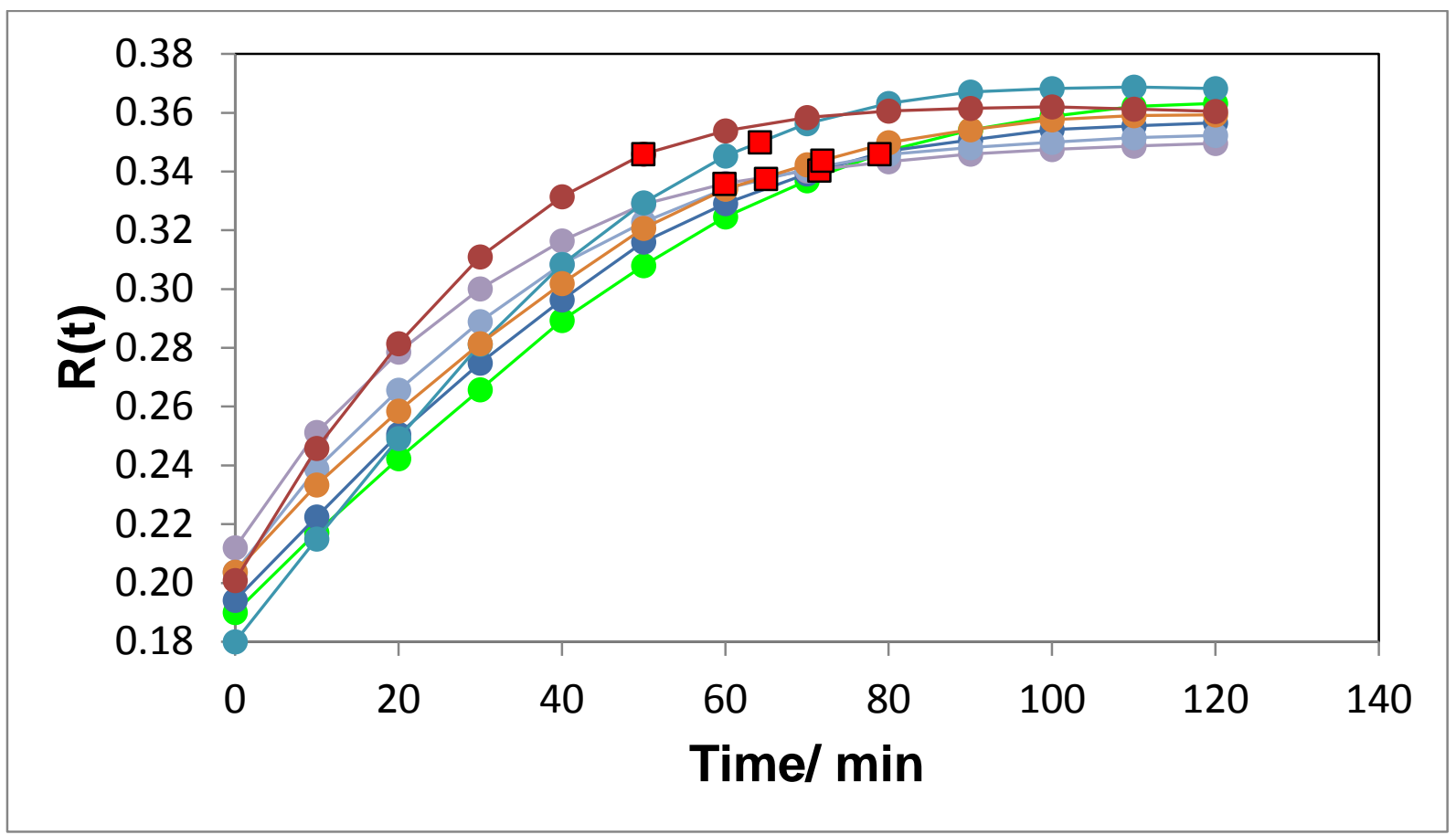

Fig. 2 Plot of R(t) depending on exposition time for Rz ink on commercial silicate based exterior paint

As a next step we exposed paints samples to an accelerated weathering test in a QUV panel to simulate weather conditions. In our previous work we reported that exposure of selfcleaning paint to extensive weathering may cause photocatalytic destruction of polymer binder and release of the embedded photocatalyst particles resulting in increase of photocatalytic activity [8, 22], eventually followed by its failure. For such exposed samples it is also convenient to use an AV7 photocatalyst activity indicator ink instead of Rz ink. The structure of AV7 dye is shown on Fig 3 and when monitoring the disappearance of its red colour, the green (G) component of the RGB analysis of the ink's image is extracted and plotted as a function of time, rather than the Blue when using the dye Resazurin. A plot of $\mathrm{G}(\mathrm{t})$ depending on time of exposition for $\mathrm{TiO}_{2}$ in-house paint is illustrated on Fig 4. Compared to bleaching curve for Rz ink (Fig 2.) we can see that the Ttb value increases and is about 46 minutes. Fig 5 illustrates the change in observed colour of the AV7 ink film, as recorded using a hand-held scanner, for an active $\mathrm{TiO}_{2}$ paint film and a reference sample (non-photocatalytic) paint sample containing only non-photoactive rutile. 


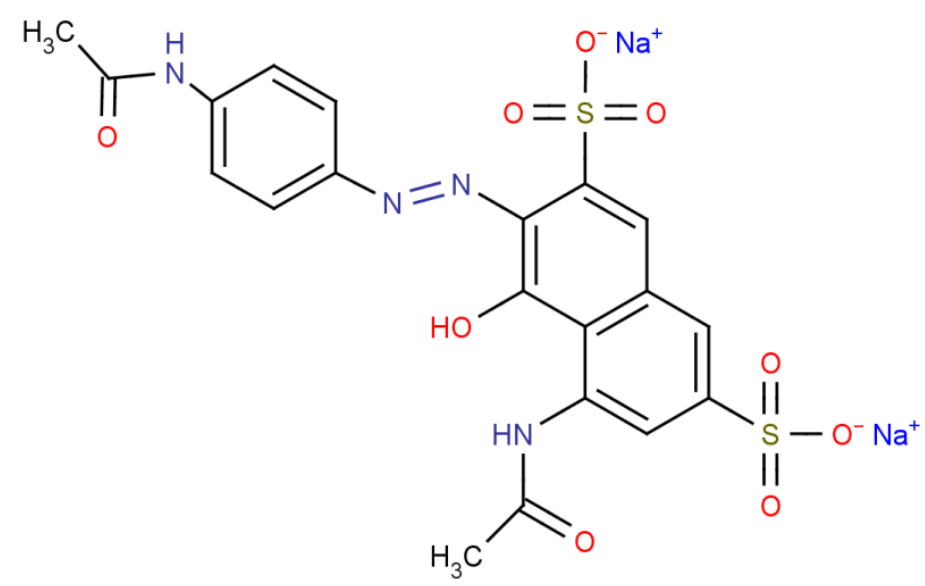

Fig. 3: Structure of AV7 dye

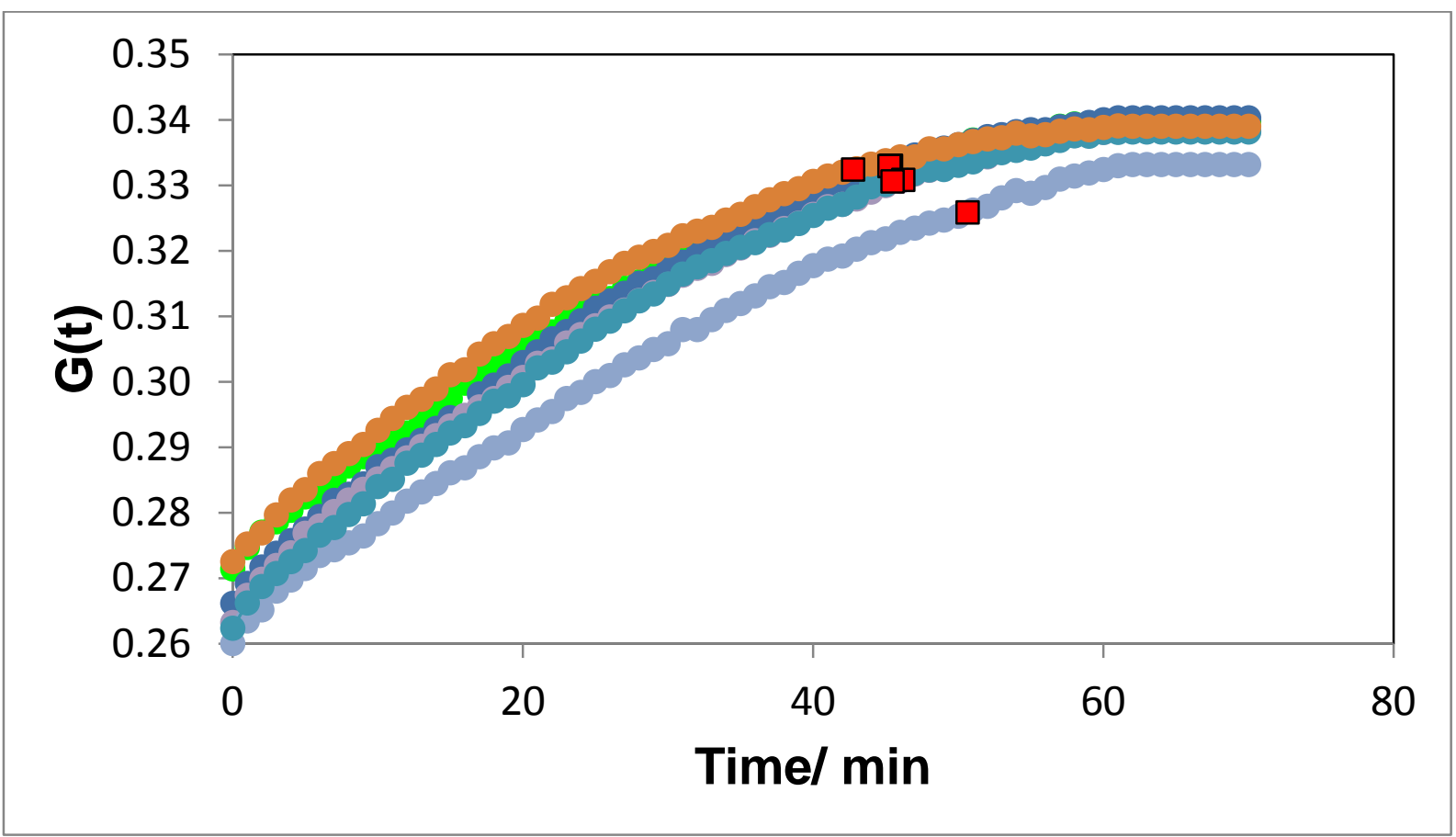

Fig 4: Plot of G(t) depending on exposition time for AV7 ink on $\mathrm{TiO}_{2}$ in-house paint 


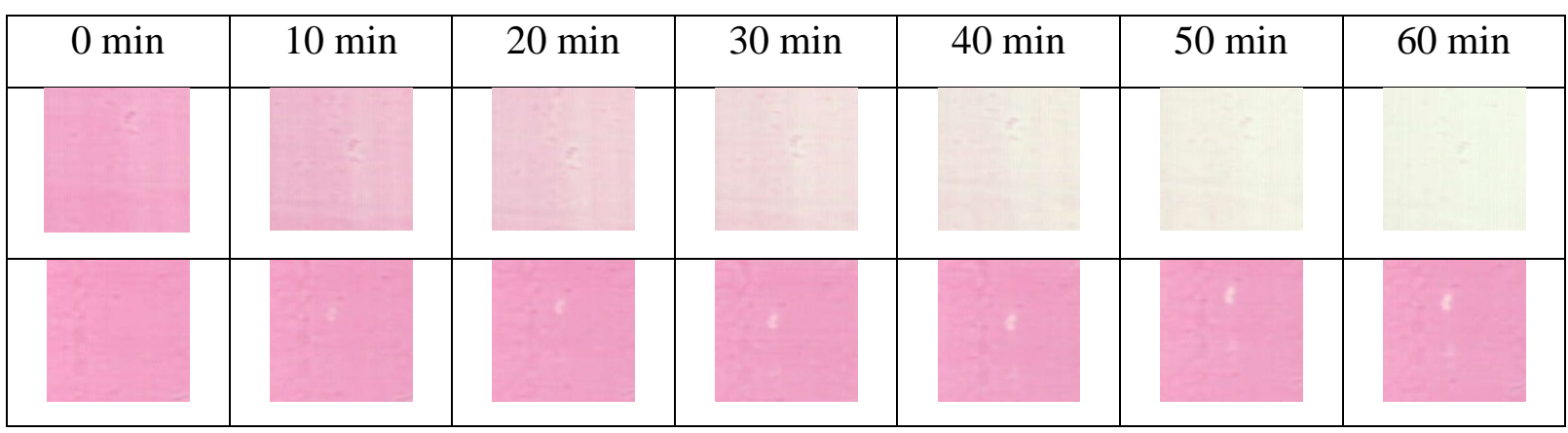

Fig 5: Example of discoloration of $\mathrm{AV7}$ ink on $\mathrm{TiO}_{2}$ paint (top) and on a reference sample without photocatalyst (bottom)

Results of calculated Ttb values for both inks are summarized in Table 1.

Tab1: Ttb(90) values for Rz and AV7 ink for unexposed paints

\begin{tabular}{|l|l|l|}
\hline & Rz ink Ttb /s & AV7 ink Ttb /s \\
\hline $\mathrm{TiO}_{2}$ paint & 83 & 2770 \\
\hline Exterior paint (EP) & 4000 & $>7000$ \\
\hline Interior paint (IP) & $<5 \mathrm{~s}$ & 356 \\
\hline
\end{tabular}

During weathering test in a QUV panel, $\mathrm{TiO}_{2}$ in-house paint seems to be almost stable. Visual observation was carried out every 150-200 h and no significant destruction of paint was observed and only small signs of chalking were visible. In contrast, in the case of commercial EP, photo-induced damage of paint was observed, so much so that on a substantial part of the substrate part the actual paint was almost completely removed (see Fig $6)$.

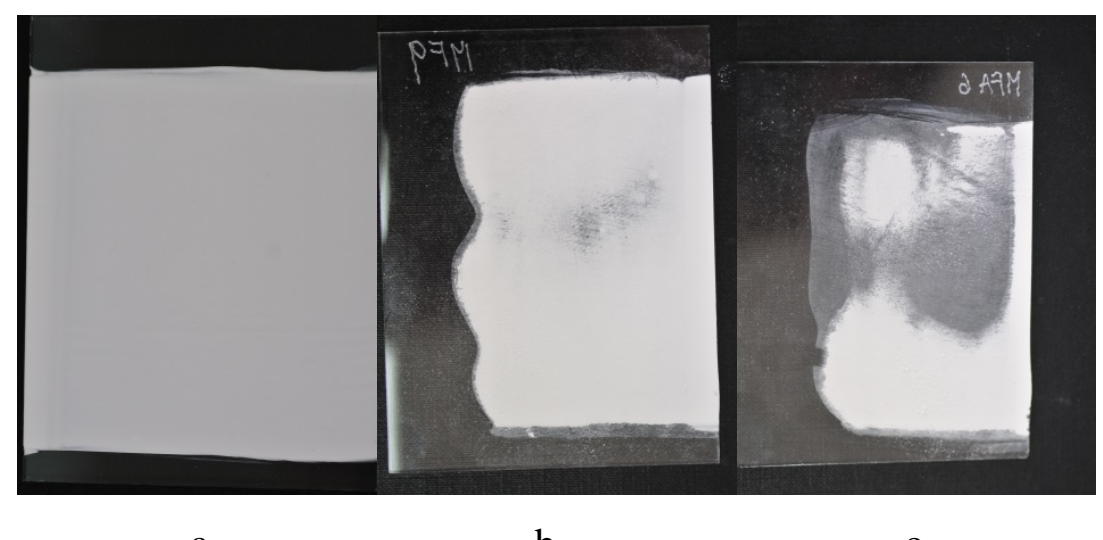

a

b

C

Fig. 6: Exterior facade paint before weathering (a), after $250 \mathrm{hr}$ (b) and after $350 \mathrm{hr}$ (c) of weathering test in QUV panel 
To determine the degree of chalking of the exterior facade paint during weathering a tape adhesion method was used. Transparent tape $(2 \mathrm{~cm}$ width) was pressed on the paint surface than the tape was torn away (see Fig. 7). We can see that before weathering the amount of white particles on the tape is negligible which suggest negligible signs of chalking. On the other side after weathering the tape after the test is full of white particles removed for the paint surface which implies a high level of chalking.

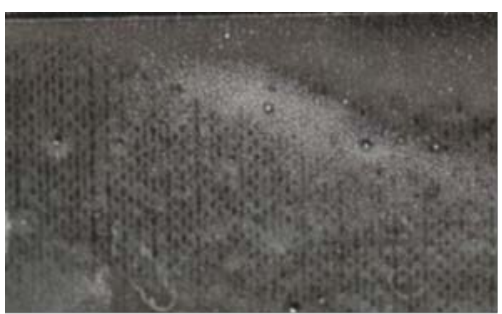

a

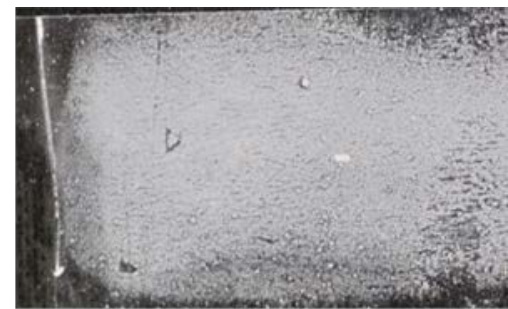

b

Fig 7 Tape adhesion test on exterior facade paint before weathering (a) and after $350 \mathrm{hr}$ (b) of weathering test in QUV panel.

The degradation of facade paint is due to the presence of the photocatalytic pigment. It is interesting that in case of interior paint (Fig 8) in which no reasonable resistance against weather conditions is assumed, the weathering test in QUV panel does not cause any significant destruction of paint film (compared to that of the silicate based exterior paint)

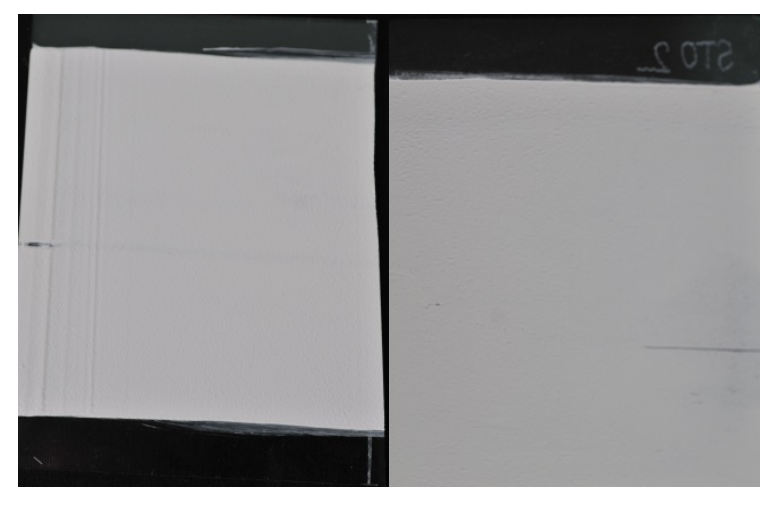

$\mathrm{a}$

b

Fig. 8: Interior paint before weathering (a) and after $500 \mathrm{hr}$ (b) of weathering test in QUV panel

As noted earlier, a measure of photocatalytic activity is provided by the reciprocal value of the measured Ttb 90 value. Dependence of 1/Ttb 90 on weathering time is illustrated in Fig 9a ( $\mathrm{TiO}_{2}$ in-house paint), Fig. 9b (interior paint) and Fig. 9c (exterior silicate based 
exterior paint). From a comparison of the data contained in Figures 9a-9c we can conclude that to develop full photocatalytic activity, a certain time of pre exposure is needed, since in all cases the photocatalytic activity during the weathering test increases. In the case of the $\mathrm{TiO}_{2}$ in-house paint the photoactivity increased 4 times after 600 hours of weathering (to $0.0013 \mathrm{~s}^{-1}$ ) and in the case of interior paint after 500 hours of weathering even ten times (to $\left.0.03 \mathrm{~s}^{-1}\right)$. A significant increase was observed also for the silicate based exterior paint in which no measurable activity (i.e. lower than $0.0001 \mathrm{~s}^{-1}$ ) using aAV7 ink was observed before weathering. But after 350 hours of weathering in QUV photocatalytic activity (AV7 ink test was performed on the parts of the paint which remained on the substrate) increased to 0.0022 $\mathrm{s}^{-1}$ which is even higher than the value for $\mathrm{TiO}_{2}$ in-house paint $\left(0.0013 \mathrm{~s}^{-1}\right)$. Interesting is the fact that the interior paint after $500 \mathrm{hr}$ of weathering shows one order of magnitude higher photocatalytic activity than the silicate based exterior paint, but, even after this weathering, the sample appears stable and no destruction of binder was observed.

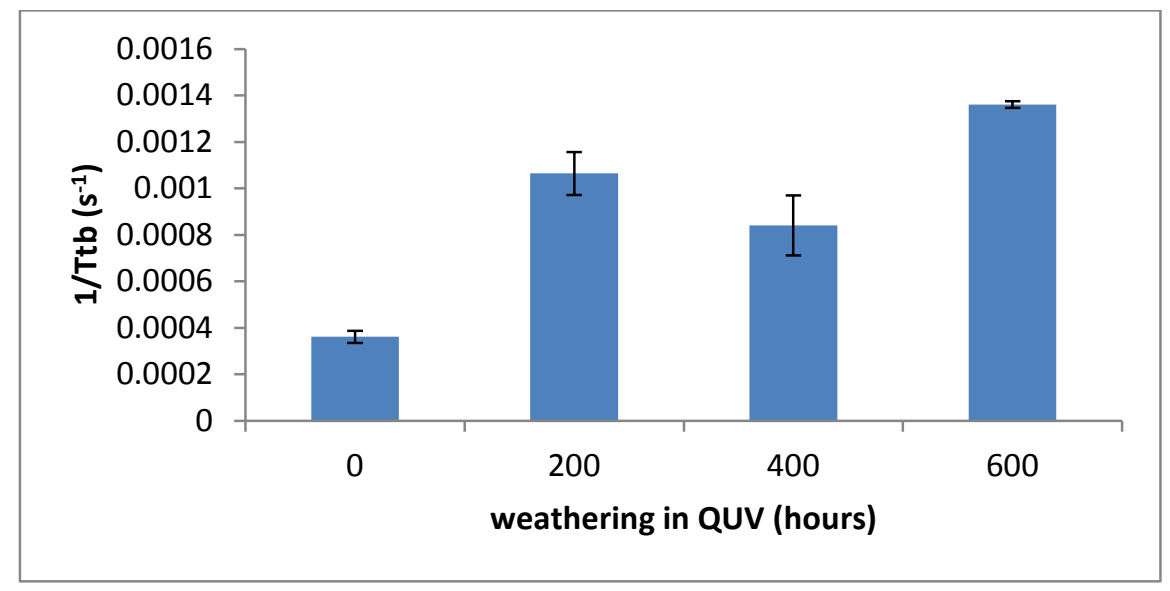

Fig.9a: Dependence of reciprocal Ttb 90 values of AV7 ink on weathering time in QUV panel for $\mathrm{TiO}_{2}$ in-house paint.

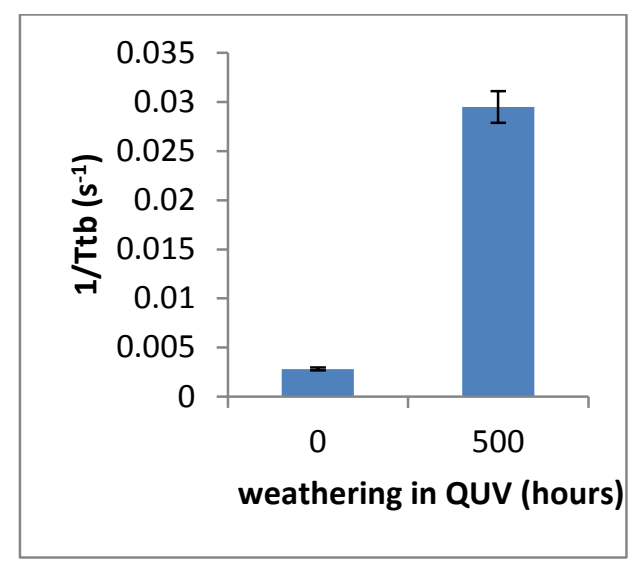


Fig. 9b: Dependence of reciprocal Ttb90 values of AV7 ink on weathering time in QUV panel for interior commercial paint

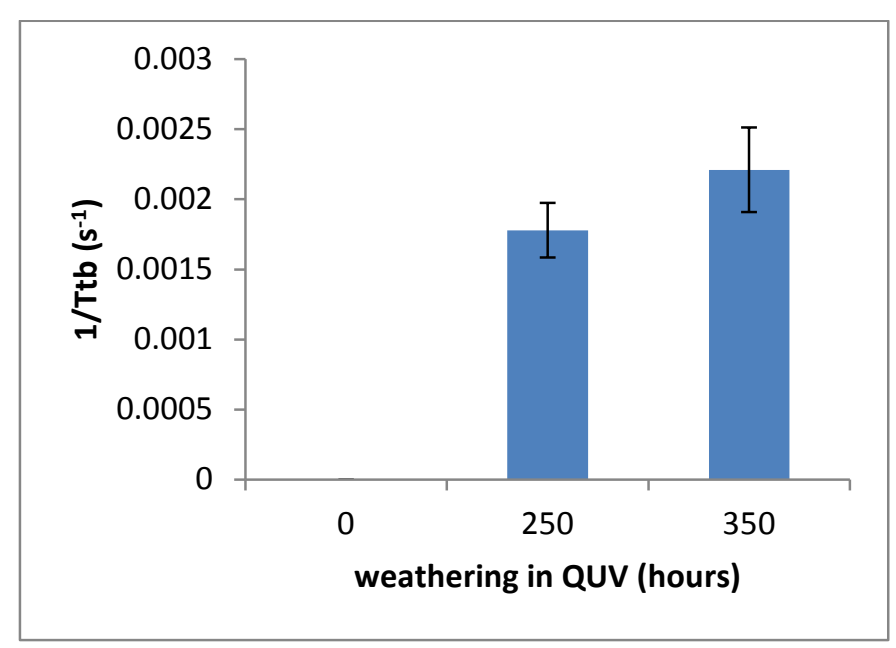

Fig. 9c: Dependence of reciprocal Ttb90 values on weathering time in QUV panel for exterior facade paint

When comparing the results of the weathering test in QUV chamber to outdoor conditions, it is necessary to have some idea of how many hours in QUV panel is equivalent to one year of outdoor exposure. The annual average sum of incident sunlight for Prague, Czech Republic is about $1068 \mathrm{kWh} / \mathrm{m}^{2}$ [23]. The incident UV light (300-400 nm) is often expressed as $4 \%$ of incident sun light. The annual average sum of incident UV light is than equal to $43 \mathrm{kWh} / \mathrm{m}^{2}$. By the integration of spectral irradiance curve $(300-400 \mathrm{~nm})$ of fluorescent tubes (used in QUV) we can obtain intensity of $52 \mathrm{~mW} / \mathrm{cm}^{2}$ [24]. The time of UV irradiation in one QUV cycle (12.2 hours) is 8 hours which means that 1 day of exposure in the QUV corresponds to the dosage of UV light (300-400 nm) equal to $974 \mathrm{Wh} / \mathrm{m}^{2}(18.73 \mathrm{~h} \mathrm{x}$ $52 \mathrm{~W} / \mathrm{m}^{2}$ ). Comparing this value with the annual average sum of incident UV light (300-400 $\mathrm{nm})$ in Prague $\left(43 \mathrm{kWh} / \mathrm{m}^{2}\right)$ we can say that in this work exposure in the QUV for 1 day corresponds roughly to 8 average days of outdoor exposure. Another, more simple, approach to estimate the relation between the time in QUV panel and outdoor exposure is based on the fact that lamps in QUV are 12 times (52/4.3) brighter than solar UV so 1 day's exposure in the weathering unit is ca. 8-12 (depending on the cycle regime in QUV) of days solar exposure.

It is important to say that the relation between exposure time in the QUV and outside exposure time can be extremely misleading [25]. The intensity of sunlight, in $\mathrm{kWh} / \mathrm{m}^{2}$, does not reflect the variation in degradation caused by temperature, moisture and wavelength. Furthermore we must take into account the fact that spectrum of natural UV light, i.e. solar $\mathrm{UV}$, is extremely variable (UV can be easily filtered by air mass, cloud cover, pollution and of 
course solar spectrum changes through the year. The weathering data for the samples in the QUV are thus mainly comparative data and we used them to compare selected photocatalytic paints.

\section{Conclusions}

Smart inks can be used to assess photocatalytic activity of various paints, interior and exterior paints with acrylate or silicate binders. Resazurin ink can be used only for less photoactive paints. Ink containing AV7 is suitable for most of the paints, especially for paints exposed to accelerated weathering test.

To reach reasonable a photocatalytic activity for paints with acrylate or silicate binders it is necessary to expose the sample to a certain time of weathering resulting in the degradation of polymer binder and unblocking of the photocatalyst surface which is then available to be effective as a photocatalyst on the inks used to assess activity. On the other hand the stability of the polymer binder must be taken in to account so as to achieve a paint which is both photocatalytically active but also has a reasonable lifetime as a paint.

\section{Acknowledgment}

Partial financial support from specific university research (MSMT No 20-SVV/2016) is acknowledged.

\section{References}

1. Gaylarde, C.C., et al., Biodeterioration of external architectural paint films - A review. International Biodeterioration \& Biodegradation, 2011. 65(8): p. 1189-1198.

2. Chen, J. and C.-s. Poon, Photocatalytic construction and building materials: From fundamentals to applications. Building and Environment, 2009. 44(9): p. 1899-1906.

3. Kaiser, J.-P., S. Zuin, and P. Wick, Is nanotechnology revolutionizing the paint and lacquer industry? A critical opinion. Science of The Total Environment, 2013. 442(0): p. 282-289.

4. Maggos, T., et al., Photocatalytic degradation of NOx in a pilot street canyon configuration using TiO2-mortar panels. Environmental Monitoring and Assessment, 2008. 136(1-3): p. 3544.

5. Guarino, M., A. Costa, and M. Porro, Photocatalytic TiO2 coating-to reduce ammonia and greenhouse gases concentration and emission from animal husbandries. Bioresource Technology, 2008. 99(7): p. 2650-2658.

6. Day, R.E., The role of titanium dioxide pigments in the degradation and stabilisation of polymers in the plastics industry. Polymer Degradation and Stability, 1990. 29(1): p. 73-92.

7. Allen, N.S., et al., Degradation and stabilisation of polymers and coatings: nano versus pigmentary titania particles. Polymer Degradation and Stability, 2004. 85(3): p. 927-946.

8. Baudys, M., et al., Weathering tests of photocatalytic facade paints containing ZnO and TiO2. Chemical Engineering Journal, 2015. 261(0): p. 83-87. 
9. Krýsa, J., et al., Photoactivity assessment of TiO2 thin films using Acid Orange 7 and 4chlorophenol as model compounds. Part I: Key dependencies. Journal of Photochemistry and Photobiology A: Chemistry, 2012. 250: p. 66-71.

10. Mills, A. and J. Wang, Simultaneous monitoring of the destruction of stearic acid and generation of carbon dioxide by self-cleaning semiconductor photocatalytic films. Journal of Photochemistry and Photobiology A: Chemistry, 2006. 182(2): p. 181-186.

11. Paz, Y., et al., Photooxidative self-cleaning transparent titanium dioxide films on glass. Journal of Materials Research, 1995. 10(11): p. 2842-2848.

12. Krýsa, J., et al., Effect of glass substrate and deposition technique on the properties of sol gel TiO2 thin films. Journal of Photochemistry and Photobiology A: Chemistry, 2011. 222(1): p. 81-86.

13. Mills, A., et al., A simple, inexpensive method for the rapid testing of the photocatalytic activity of self-cleaning surfaces. Journal of Photochemistry and Photobiology A: Chemistry, 2013. 272(0): p. 18-20.

14. Kafizas, A., A. Mills, and I.P. Parkin, A comprehensive aerosol spray method for the rapid photocatalytic grid area analysis of semiconductor photocatalyst thin films. Analytica Chimica Acta, 2010. 663(1): p. 69-76.

15. Krýsa, J., M. Baudys, and A. Mills, Quantum yield measurements for the photocatalytic oxidation of Acid Orange 7 (AO7) and reduction of 2,6-dichlorindophenol (DCIP) on transparent TiO2 films of various thickness. Catalysis Today, 2015. 240, Part A(0): p. 132-137.

16. Mills, A., J. Hepburn, and M. McFarlane, A Novel, Fast-Responding, Indicator Ink for Thin Film Photocatalytic Surfaces. ACS Applied Materials \& Interfaces, 2009. 1(6): p. 1163-1165.

17. Mills, A. and M. McGrady, A study of new photocatalyst indicator inks. Journal of Photochemistry and Photobiology A: Chemistry, 2008. 193(2-3): p. 228-236.

18. Mills, A., N. Wells, and C. O'Rourke, Correlation between $\triangle A b s, \triangle R G B$ (red) and stearic acid destruction rates using commercial self-cleaning glass as the photocatalyst. Catalysis Today, 2014. 230(0): p. 245-249.

19. Zita, J., J. Krýsa, and A. Mills, Correlation of oxidative and reductive dye bleaching on TiO2 photocatalyst films. Journal of Photochemistry and Photobiology A: Chemistry, 2009. 203(23): p. 119-124.

20. Mills, A., et al., Photocatalytic activity indicator inks for probing a wide range of surfaces. Journal of Photochemistry and Photobiology a-Chemistry, 2014. 290: p. 63-71.

21. ISO 10677: 2011, 'Fine ceramics, advanced technical ceramics - ultraviolet light source for testing semiconducting photocatalytic materials', ISO, Geneva, 2011.

22. Mills, A., C. Hill, and P.K.J. Robertson, Overview of the current ISO tests for photocatalytic materials. Journal of Photochemistry and Photobiology A: Chemistry, 2012. 237(0): p. 7-23.

23. Huld, T. and I. Pinedo-Pascua. Global irradiation and solar electricity potential. Available from: http://re.jrc.ec.europa.eu/pvgis/cmaps/eu cmsaf hor/G hor CZ.pdf.

24. Sunlight, Weathering \& Light Stability Testing. Technical bulletin LU-0822. Q Lab.

25. Grossman, D.M., Correlation Qusteions \& Answers. Technical Bulletin LU-0833, Q-LAB, Editor. 